\title{
High-quality draft genome sequence of Rhizobium mesoamericanum strain STM6155, a Mimosa pudica microsymbiont from New Caledonia
}

Agnieszka Klonowska ${ }^{1,2}$, Aline López-López ${ }^{2}$, Lionel Moulin ${ }^{1,2}$, Julie Ardley³ ${ }^{3}$, Margaret Gollagher ${ }^{4}$, Dora Marinova ${ }^{4}$, Rui Tian ${ }^{3}$, Marcel Huntemann ${ }^{5}$, T.B.K. Reddy ${ }^{5}$, Neha Varghese ${ }^{5}$, Tanja Woyke ${ }^{5}$, Victor Markowitz ${ }^{6}$, Natalia Ivanova ${ }^{5}$, Rekha Seshadri ${ }^{5}$, Mohamed N. Baeshen ${ }^{7}$, Nabih A. Baeshen ${ }^{8}$, Nikos Kyrpides $^{5,8}$ and Wayne Reeve ${ }^{3^{*}}$

\begin{abstract}
Rhizobium mesoamericanum STM6155 (INSCD = ATYY01000000) is an aerobic, motile, Gram-negative, non-sporeforming rod that can exist as a soil saprophyte or as an effective nitrogen fixing microsymbiont of the legume Mimosa pudica L.. STM6155 was isolated in 2009 from a nodule of the trap host M. pudica grown in nickel-rich soil collected near Mont Dore, New Caledonia. R. mesoamericanum STM6155 was selected as part of the DOE Joint Genome Institute 2010 Genomic Encyclopedia for Bacteria and Archaea-Root Nodule Bacteria (GEBA-RNB) genome sequencing project. Here we describe the symbiotic properties of $R$. mesoamericanum STM6155, together with its genome sequence information and annotation. The 6,927,906 bp high-quality draft genome is arranged into 147 scaffolds of 152 contigs containing 6855 protein-coding genes and 71 RNA-only encoding genes. Strain STM6155 forms an ANI clique (ID 2435) with the sequenced R. mesoamericanum strain STM3625, and the nodulation genes are highly conserved in these strains and the type strain of Rhizobium grahamii CCGE501 ${ }^{\top}$. Within the STM6155 genome, we have identified a chr chromate efflux gene cluster of six genes arranged into two putative operons and we postulate that this cluster is important for the survival of STM6155 in ultramafic soils containing high concentrations of chromate.
\end{abstract}

Keywords: Root-nodule bacteria, Nitrogen fixation, Rhizobium, Alphaproteobacteria, Mimosa

\section{Introduction}

The ability of legumes to engage in a dinitrogen fixing symbiosis with soil dwelling bacteria, collectively known as rhizobia, has contributed to their success in colonizing nitrogen deficient soils over a broad range of edaphic conditions. While legume crops and pastures make important contributions to agricultural productivity, invasive legume weeds such as Mimosa pudica L. have a negative impact on natural and agricultural ecological systems. M. pudica originates from America [1] and became a highly invasive pantropical weed. It has been identified as a pest species, associated with land degradation, biodiversity loss, and

\footnotetext{
* Correspondence: W.Reeve@murdoch.edu.au

${ }^{3}$ School of Veterinary and Life Sciences, Murdoch University, Murdoch, WA, Australia

Full list of author information is available at the end of the article
}

reduced agricultural and therefore economic productivity, with attendant social and health impacts [2]. It requires resource-intensive chemical and mechanical control methods [2]. Conversely, however, it has potential commercial value as a source of silver nanoparticles and pharmacologically active phytochemicals, and as a phytoremediant for arsenic-polluted soils [3-6]. Understanding the Mimosa symbiosis can therefore help to achieve outcomes such as preventing biodiversity loss and improving the use of terrestrial ecosystems, as well as promoting sustainable industry, which form part of the Sustainable Development Goals adopted in September 2015 as part of the UN's development agenda 'Transforming our world: the 2030 Agenda for Sustainable Development' [7].

M. pudica has the unusual property of interacting with microsymbionts belonging to both alpha- and beta-rhizobia 


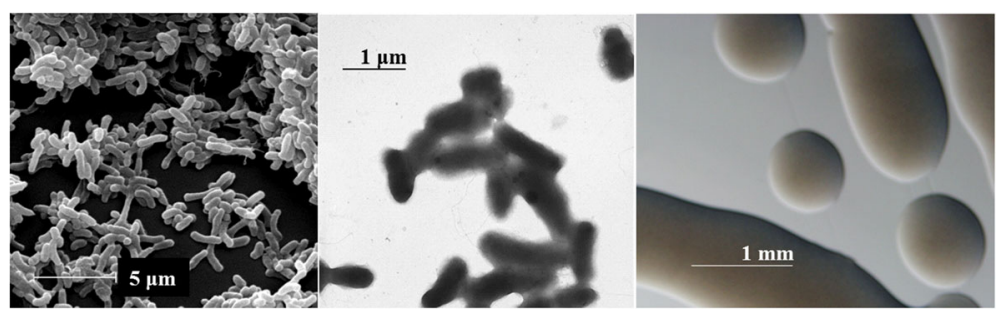

Fig. 1 Images of Rhizobium mesoamericanum STM6155 using scanning (Left) and transmission (Center) electron microscopy and the appearance of colony morphology on solid media (Right)

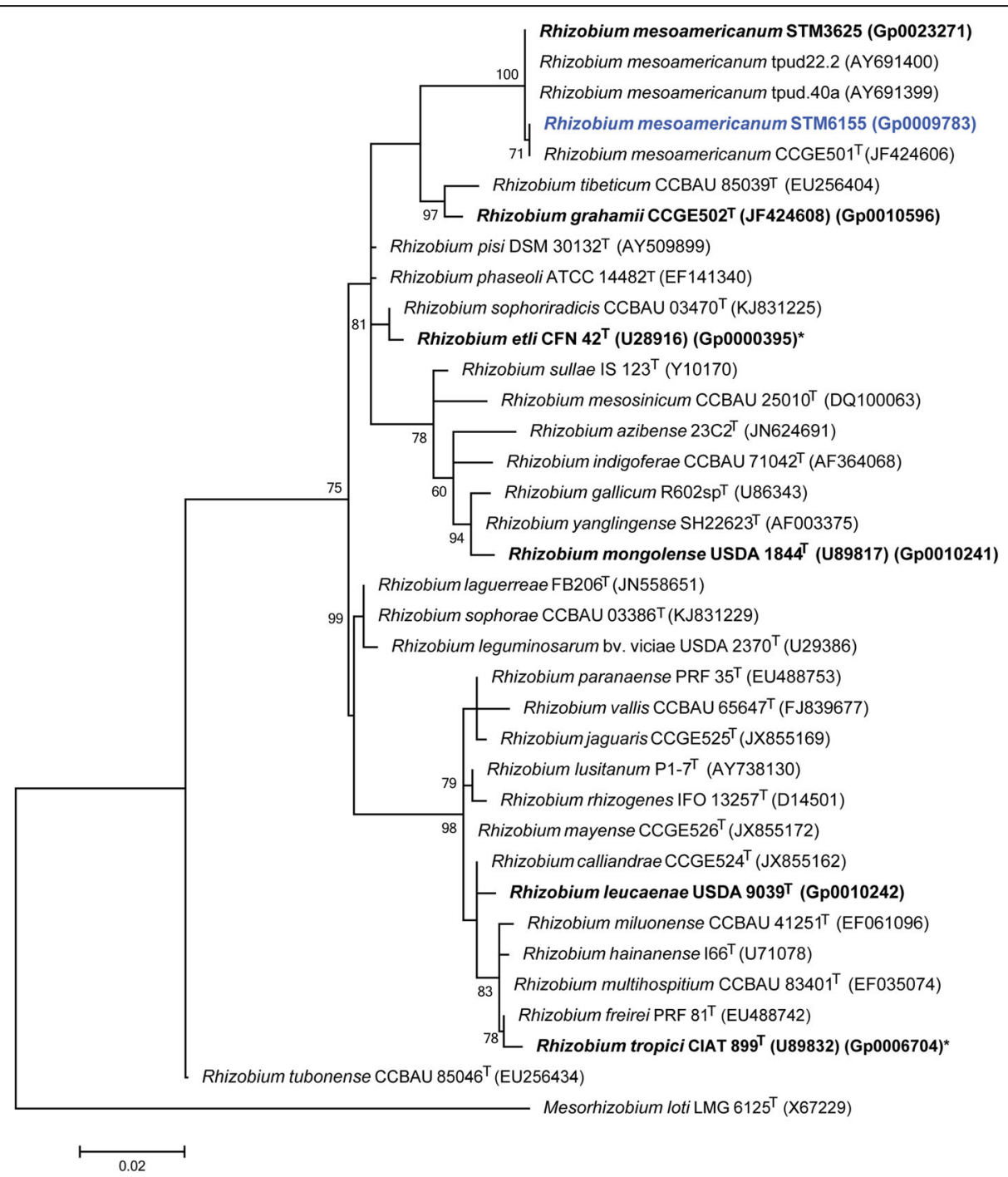

Fig. 2 Phylogenetic tree showing the relationship of Rhizobium mesoamericanum STM6155 (shown in bold blue print) to Rhizobium spp. and other root nodule bacteria in the order Rhizobiales based on aligned sequences of the $16 \mathrm{~S}$ rRNA gene (1286 bp intragenic sequence). Mesorhizobium loti LMG6125 ${ }^{\top}$ was used as an outgroup. All sites were informative and there were no gap-containing sites. Phylogenetic analyses were performed using MEGA, version 5 [53]. The tree was built using the Maximum-Likelihood method with the General Time Reversible model [54]. Bootstrap analysis [55] with 500 replicates was performed to assess the support of the clusters. Type strains are indicated with a superscript T. Strains with a genome sequencing project registered in GOLD [31] are in bold font and the GOLD ID is provided after the GenBank accession number, where this is available. Finished genomes are indicated with an asterisk 
[8, 9]. Alpha-rhizobia are preferred symbionts of most legume species, but beta-rhizobia have a far narrower host range, with a particular affinity for the Mimosa genus in South America [10] and endemic papilionoid species in South Africa [11]. Diversity studies have shown that alpharhizobia are found less frequently than beta-rhizobia in the nodules of $M$. pudica [12-17], and nodulating species exhibit different competitive and symbiotic characteristics $[18,19]$. M. pudica thus represents an interesting legume species for comparative analyses of symbiotic traits and plant-infection genetic programs in the two categories of symbionts.

M. pudica was introduced to New Caledonia at the end of the $19^{\text {th }}$ century [15]. Rhizobium mesoamericanum STM6155 was isolated from nodules of $M$. pudica growing in soil characterized by neutral $\mathrm{pH}(6.8)$ and very high total nickel concentrations $\left(10.1\right.$ g. $\left.\mathrm{kg}^{-1}\right)$ that was collected near the abandoned nickel mining site of Mont Dore (S3: $22^{\circ} 15^{\prime} 16.51^{\prime \prime} \mathrm{S}$ and $166^{\circ} 36^{\prime} 44.27^{\prime \prime} \mathrm{E}$ ) in New Caledonia [15].

The 16S rRNA and recA house-keeping genes of STM6155 showed 100 and 97\% nucleotide identity with their orthologs in Rhizobium mesoamericanum CCGE501 ${ }^{\mathrm{T}}$ from Mexico [20], and STM6155 was thus tentatively included in the same species. Among described alpharhizobial symbionts of $M$. pudica (R. etli bv. mimosae, $R$. tropici and $R$. mesoamericanum), $R$. mesoamericanum is the most frequently detected species, with a distribution on different continents (Central \& South America, Asia) $[17,20]$. In Mexico, endemic Mimosa spp. growing in weakly acidic, neutral or slightly alkaline soil are preferentially nodulated by Alphaproteobacterial rhizobia, including

Table 1 Classification and general features of Rhizobium mesoamericanum STM6155 in accordance with the MIGS recommendations [56] published by the Genome Standards Consortium [57]

\begin{tabular}{|c|c|c|c|}
\hline MIGS ID & Property & Term & Evidence code ${ }^{a}$ \\
\hline & Classification & Domain Bacteria & TAS [58] \\
\hline & & Phylum Proteobacteria & $\operatorname{TAS}[59,60]$ \\
\hline & & Class Alphaproteobacteria & $\operatorname{TAS}[59,61]$ \\
\hline & & Order Rhizobiales & TAS [62] \\
\hline & & Family Rhizobiaceae & TAS [63] \\
\hline & & Genus Rhizobium & TAS [15] \\
\hline & & Species mesoamericanum & $\operatorname{TAS}[15,20]$ \\
\hline & Gram stain & Negative & IDA \\
\hline & Cell shape & Rod & IDA \\
\hline & Motility & Motile & IDA \\
\hline & Sporulation & Non-sporulating & NAS \\
\hline & Temperature range & Mesophile & NAS \\
\hline & Optimum temperature & $28^{\circ} \mathrm{C}$ & NAS \\
\hline & $\mathrm{pH}$ range; Optimum & 7.0 & $\operatorname{TAS}[15,20]$ \\
\hline & Carbon source & Varied; includes mannitol & $\operatorname{TAS}[15,20]$ \\
\hline MIGS-6 & Habitat & Soil, root nodule on host & TAS [15] \\
\hline MIGS-6.3 & Salinity & Up to $1.5 \%$ but not $3 \% \mathrm{NaCl}(\mathrm{w} / \mathrm{v})$ & $\operatorname{TAS}[15,20]$ \\
\hline MIGS-22 & Oxygen requirement & Aerobic & TAS [15] \\
\hline MIGS-15 & Biotic relationship & Free-living/symbiont & TAS [15] \\
\hline \multirow[t]{3}{*}{ MIGS-14 } & Pathogenicity & Non-pathogenic & NAS \\
\hline & Biosafety level & 1 & TAS [64] \\
\hline & Isolation & Root nodule of Mimosa pudica $\mathrm{L}$. & TAS [15] \\
\hline MIGS-4 & Geographic location & Proximity of Mont Dore, New Caledonia & TAS [15] \\
\hline MIGS-5 & Sample collection & 2009 & TAS [15] \\
\hline MIGS-4.1 & Latitude & 166.612297 & TAS [15] \\
\hline MIGS-4.2 & Longitude & -22.254586 & TAS [15] \\
\hline MIGS-4.4 & Altitude & $112 \mathrm{~m}$ & TAS [15] \\
\hline
\end{tabular}

Evidence codes - IDA inferred from direct assay, TAS traceable author statement (i.e., a direct report exists in the literature), NAS non-traceable author statement (i.e., not directly observed for the living, isolated sample, but based on a generally accepted property for the species, or anecdotal evidence) These evidence codes are from the Gene Ontology project $[65,66]$ 
strains of R. mesoamericanum [21], whereas acid-tolerant Burkholderia spp. are favoured microsymbionts of endemic Mimosa spp., including M. pudica, in acidic Brazilian soils $[14,22]$. $R$. mesoamericanum is much less effective for nitrogen fixation on M. pudica than Burkholderia phymatum STM815 or Cupriavidus taiwanensis STM6070 [12, 15], and much less competitive in comparison to $B$. phymatum and $B$. tuberum [19]. These data question how $R$. mesoamericanum can maintain itself as a symbiont of M. pudica despite its low competitiveness. Strain STM6155 has therefore been selected as part of the DOE Joint Genome Institute 2010 Genomic Encyclopedia for Bacteria and Archaea-Root Nodule Bacteria (GEBA-RNB) sequencing project $[23,24]$, to investigate the genome traits that enable this species to adapt to a symbiotic and saprophytic lifestyle. Here we present a summary classification and a set of general features for $R$. mesoamericanum STM6155, together with a description of its genome sequence and annotation.

\section{Organism information} Classification and features

Rhizobium mesoamericanum STM6155 is a motile, Gram-negative, non-spore forming strain in the order Rhizobiales of the class Alphaproteobacteria. The rod-shaped form has dimensions of $0.4-0.6 \mu \mathrm{m}$ in width and 1.0 $1.4 \mu \mathrm{m}$ in length (Fig. 1 Left and Center). It is fast growing, forming colonies within 3-4 days when grown on half strength Lupin Agar ( $1 / 2 \mathrm{LA})$ [25], tryptone-yeast extract agar (TY) [26] or a modified yeast-mannitol agar [27] at $28{ }^{\circ} \mathrm{C}$. Colonies on $1 / 2 \mathrm{LA}$ are white-opaque, slightly domed and moderately mucoid with smooth margins (Fig. 1 Right).

Figure 2 shows the phylogenetic relationship of $R$. mesoamericanum STM6155 in a 16S rRNA sequence based tree. This strain is the most similar to $R$. mesoamericanum CCGE $501^{\mathrm{T}}$ based on the $16 \mathrm{~S}$ rRNA gene alignment, with sequence identities of 100\% over $1362 \mathrm{bp}$, as determined using the EzTaxon-e database, which contains the sequences of validly published type strains [28]. Minimum Information about the Genome Sequence for STM6155 is provided in Table 1 and Additional file 1: Table S1.

\section{Symbiotaxonomy}

R. mesoamericanum STM6155 was isolated from nodules of $M$. pudica, as were others members of this species including STM3625, STM3629, tpud40a and tpud22.2 $[12,15,17]$. However, the type strain of the species, CCGE501 ${ }^{\mathrm{T}}$, originates from nodules of Phaseolus vulgaris L. [20]. Strain STM6155 forms nodules and fixes $\mathrm{N}_{2}$ with several Mimosa species of American origin, including M. pudica and Mimosa acustipulata Benth. It forms white, ineffective nodules on Mimosa pigra L. and Mimosa caesalpinifolia Benth. but is unable to nodulate Mimosa scabrella Benth. STM6155 is also able to form
Table 2 Genome sequencing project information for Rhizobium mesoamericanum STM6155

\begin{tabular}{lll}
\hline MIGS ID & Property & Term \\
\hline MIGS 31 & Finishing quality & High-quality draft \\
MIGS-28 & Libraries used & 1x Illumina Std PE library \\
MIGS 29 & Sequencing platforms & Illumina HiSeq 2000 \\
MIGS 31.2 & Fold coverage & Illumina: 279x \\
MIGS 30 & Assemblers & Velvet version 1.1.04; Allpaths-LG \\
& & version r39750 \\
MIGS 32 & Gene calling method & Prodigal 1.4 \\
& Locus Tag & YY3 [67] \\
& Genbank ID & ATYY00000000 \\
& GenBank Date of Release & 15 $5^{\text {th }}$ July 2013 \\
& GOLD ID & Gp0009783 \\
& NCBI BIOPROJECT & 163057 \\
MIGS 13 & Source Material Identifier & STM6155, WSM4584 \\
& Project relevance & Symbiotic N fixation, agriculture \\
\hline
\end{tabular}

nitrogen-fixing nodules on $P$. vulgaris and on a legume, Acacia spirorbis Labill., which grows in the same area from which STM6155 originates [15]. The symbiotic characteristics of $R$. mesoamericanum STM6155 on a range of hosts are summarised in Additional file 1: Table S2. $R$. mesoamericanum STM6155 contains a full set of nodulation genes, and exhibits uncommon features, such as the presence of two alleles of the nodA gene in its genome, a feature that seems conserved in several strains of the species such as STM3625 $[15,17,29]$.

Table 3 Genome statistics for Rhizobium mesoamericanum STM6155

\begin{tabular}{lrr}
\hline Attribute & \multicolumn{1}{c}{ Value } & \% of Total \\
\hline Genome size (bp) & $6,927,906$ & 100.00 \\
DNA coding (bp) & $6,004,006$ & 86.66 \\
DNA G + C (bp) & $4,080,584$ & 58.90 \\
DNA scaffolds & 147 & \\
Total genes & 6926 & 100.00 \\
Protein coding genes & 6855 & 98.97 \\
RNA genes & 71 & 1.03 \\
Pseudo genes & 0 & 0.00 \\
Genes in internal clusters & 1382 & 19.95 \\
Genes with function prediction & 5265 & 76.02 \\
Genes assigned to COGs & 4585 & 66.20 \\
Genes with Pfam domains & 5490 & 79.27 \\
Genes with signal peptides & 538 & 7.77 \\
Genes with transmembrane helices & 1529 & 22.08 \\
CRISPR repeats & 0 & 0.00 \\
\hline
\end{tabular}




\section{Genome sequencing information}

\section{Genome project history}

This organism was selected for sequencing at the U.S. Department of Energy funded Joint Genome Institute as part of the Genomic Encyclopedia of Bacteria and ArchaeaRoot Nodule Bacteria (GEBA-RNB) project [23, 24]. The root nodule bacteria in this project were selected on the basis of environmental and agricultural relevance to issues in global carbon cycling, alternative energy production, and biogeochemical importance. The genome project is deposited in the Genomes On-Line Database [30] and a high-quality permanent draft genome sequence is deposited in IMG [31]. Sequencing, finishing and annotation were performed by the JGI. A summary of the project information is shown in Table 2.

\section{Growth conditions and genomic DNA preparation}

Rhizobium mesoamericanum STM6155 was streaked onto TY solid medium [26] and grown at $28^{\circ} \mathrm{C}$ for 3 days to obtain well grown, well separated colonies, then a single colony was selected and used to inoculate $5 \mathrm{ml}$ TY broth medium. The culture was grown for $48 \mathrm{~h}$ on a gyratory shaker $(200 \mathrm{rpm})$ at $28{ }^{\circ} \mathrm{C}$. Subsequently $1 \mathrm{ml}$

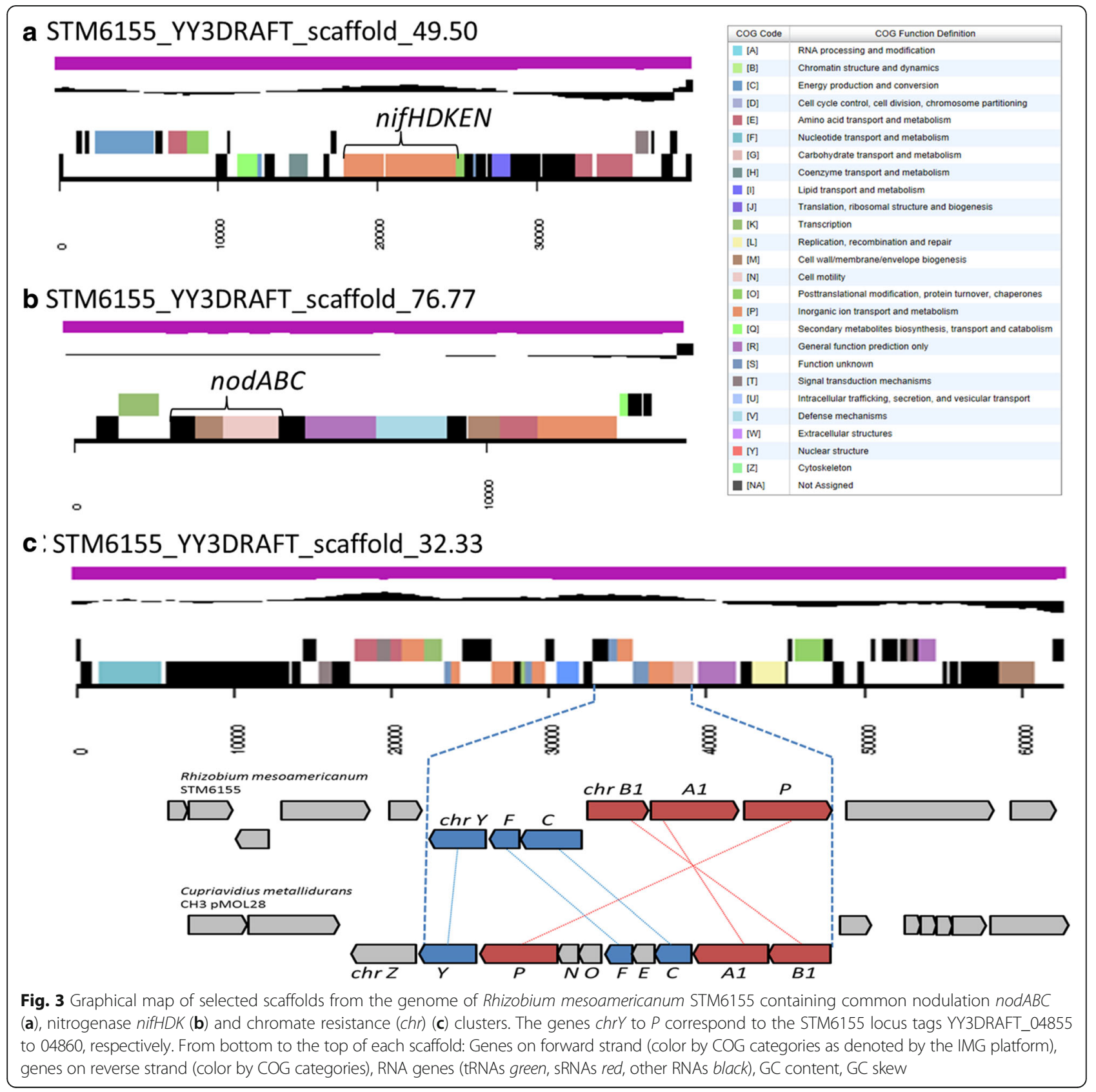


Table 4 Number of genes of Rhizobium mesoamericanum STM6155 associated with general COG functional categories

\begin{tabular}{|c|c|c|c|}
\hline Code & Value & \%age & Description \\
\hline J & 215 & 4.13 & Translation, ribosomal structure and biogenesis \\
\hline A & 0 & 0.00 & RNA processing and modification \\
\hline K & 462 & 8.87 & Transcription \\
\hline L & 141 & 2.71 & Replication, recombination and repair \\
\hline B & 1 & 0.02 & Chromatin structure and dynamics \\
\hline D & 41 & 0.79 & Cell cycle control, cell division, chromosome partitioning \\
\hline V & 120 & 2.30 & Defense mechanisms \\
\hline T & 236 & 4.53 & Signal transduction mechanisms \\
\hline M & 283 & 5.43 & Cell wall/membrane/envelope biogenesis \\
\hline N & 74 & 1.42 & Cell motility \\
\hline W & 17 & 0.33 & Extracellular structures \\
\hline$U$ & 90 & 1.73 & Intracellular trafficking, secretion and vesicular transport \\
\hline O & 191 & 3.67 & Posttranslational modification, protein turnover, chaperones \\
\hline C & 324 & 6.22 & Energy production and conversion \\
\hline G & 463 & 8.89 & Carbohydrate transport and metabolism \\
\hline E & 593 & 11.38 & Amino acid transport and metabolism \\
\hline $\mathrm{F}$ & 104 & 2.00 & Nucleotide transport and metabolism \\
\hline H & 248 & 4.76 & Coenzyme transport and metabolism \\
\hline । & 239 & 4.59 & Lipid transport and metabolism \\
\hline$P$ & 259 & 4.97 & Inorganic ion transport and metabolism \\
\hline Q & 162 & 3.11 & Secondary metabolites biosynthesis, transport and catabolism \\
\hline R & 556 & 10.67 & General function prediction only \\
\hline S & 324 & 6.22 & Function unknown \\
\hline - & 2341 & 33.80 & Not in COGs \\
\hline
\end{tabular}

was used to inoculate $60 \mathrm{ml}$ TY broth medium and the cells were incubated at $28{ }^{\circ} \mathrm{C}$ on a gyratory shaker at 200 rpm until an $\mathrm{OD}_{600 \mathrm{~nm}}$ of 0.6 was reached. DNA was isolated from $60 \mathrm{ml}$ of cells using a CTAB bacterial genomic DNA isolation method [32]. Final concentration of the DNA was set to $0.5 \mathrm{mg} \mathrm{ml}^{-1}$.

\section{Genome sequencing and assembly}

The draft genome of $R$. mesoamericanum STM6155 was generated at the JGI using Illumina technology [33]. An
Illumina standard shotgun library was constructed and sequenced using the Illumina HiSeq 2000 platform which generated 14,034,164 reads totaling $2105 \mathrm{Mbp}$. All general aspects of library construction and sequencing performed at the JGI can be found on the JGI website [34]. All raw Illumina sequence data was passed through DUK, a filtering program developed at JGI, which removes known Illumina sequencing and library preparation artifacts (Mingkun L, Copeland A, Han J. unpublished), providing 12,829,288 trimmed reads totaling $1924 \mathrm{Mbp}$. The

Table 5 Percentage of Average Nucleotide Identities (ANI) ${ }^{\mathrm{a}}$ among Rhizobium genomes

\begin{tabular}{|c|c|c|c|c|c|c|}
\hline Strain & 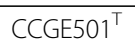 & STM3625 & STM6155 & CFN $42^{\top}$ & Mim1 & CIAT899 $^{\top}$ \\
\hline R. mesoamericanum CCGE $501^{\top}$ & - & 96.55 & 96.17 & 84.28 & 84.6 & 84.69 \\
\hline R. mesoamericanum STM3625 & 96.55 & - & 96.41 & 84.4 & 85.19 & 85.03 \\
\hline R. mesoamericanum STM6155 & 96.18 & 96.44 & - & 84.45 & 85.31 & 84.97 \\
\hline R. etli CFN42 ${ }^{\top}$ & 84.25 & 84.4 & 84.42 & - & 98.58 & 84.45 \\
\hline R. etli bv. mimosae Mim1 & 84.59 & 85.16 & 85.3 & 98.6 & - & 84.71 \\
\hline R. tropici CIAT $899^{\top}$ & 84.72 & 85.0 & 85.03 & 84.43 & 84.74 & - \\
\hline
\end{tabular}

${ }^{\mathrm{a}} \mathrm{ANI}$ values were calculated with jSpecies (based on whole genome Mummer alignments) [68]. Genomes were downloaded from Genbank accessions when already published except $R$. mesoamericanum $\mathrm{CCGE} 501^{\top}$ for which the draft genome was kindly provided by E. Martínez-Romero. Values in bold indicate values above the species cut-off (at least $95 \%$ on $69 \%$ of conserved DNA) [46] 
following steps were then performed for assembly: 1) filtered Illumina reads were assembled using Velvet [35] (version 1.1.04); 2) 1-3 Kbp simulated paired end reads were created from Velvet contigs using wgsim [36]; 3) Illumina reads were assembled with simulated read pairs using Allpaths-LG [37] (version r39750). Parameters for assembly steps were: 1) Velvet (velveth: $-\mathrm{v}-\mathrm{s} 51$-e 71 -i 2 -t 1 -f "-shortPaired -fastq \$FASTQ" -o "-ins_length 250 -min_contig_lgth 500"); 2) wgsim -e 0 -1 76 -2 76 -r 0 -R $\quad 0 \quad-X \quad 0) ; 3)$ Allpaths-LG (PrepareAllpathsInputs: $\mathrm{PHRED64}=1$ PLOIDY $=1$ FRAGCOVERAGE $=125$ JUMPCOVERAGE $=25$ LONGJUMPCOV $=50$, RunAllpathsLG: THREADS $=8$ RUN $=$ stdshredpairs TARGETS $=$ standard VAPIWARNONLY $=$ True OVERWRITE $=$ True $)$. The final draft assembly contained 152 contigs in 147 scaffolds. The total size of the genome is $6.9 \mathrm{Mbp}$ and the final assembly is based on $1924 \mathrm{Mbp}$ of Illumina data, which provides an average $279 x$ coverage of the genome.

\section{Genome annotation}

Genes were identified using Prodigal [38] as part of the DOE-JGI annotation pipeline [39, 40]. The predicted CDSs were translated and used to search the National
Center for Biotechnology Information nonredundant database, UniProt, TIGRFam, Pfam, PRIAM, KEGG, COG, and InterPro databases. The tRNAScanSE tool [41] was used to find tRNA genes, whereas ribosomal RNA genes were found by searches against models of the ribosomal RNA genes built from SILVA [42]. Other non-coding RNAs such as the RNA components of the protein secretion complex and the RNase P were identified by searching the genome for the corresponding Rfam profiles using INFERNAL [43]. Additional gene prediction analysis and manual functional annotation was performed within the Integrated Microbial Genomes - Expert Review platform [44] developed by the Joint Genome Institute, Walnut Creek, CA, USA. The annotated genome of $R$. mesoamericanum STM6155 is available in IMG (genome ID $=2513237088$ ).

\section{Genome properties}

The genome is 6,927,906 nucleotides with $58.90 \%$ GC content (Table 3) and comprised of 147 scaffolds (selected scaffolds are shown in Fig. 3) of 152 contigs. The location of nodulation (Fig. 3a), nitrogenase (Fig. 3b) and chromate resistance (Fig. 3c) loci on genome scaffolds are shown.

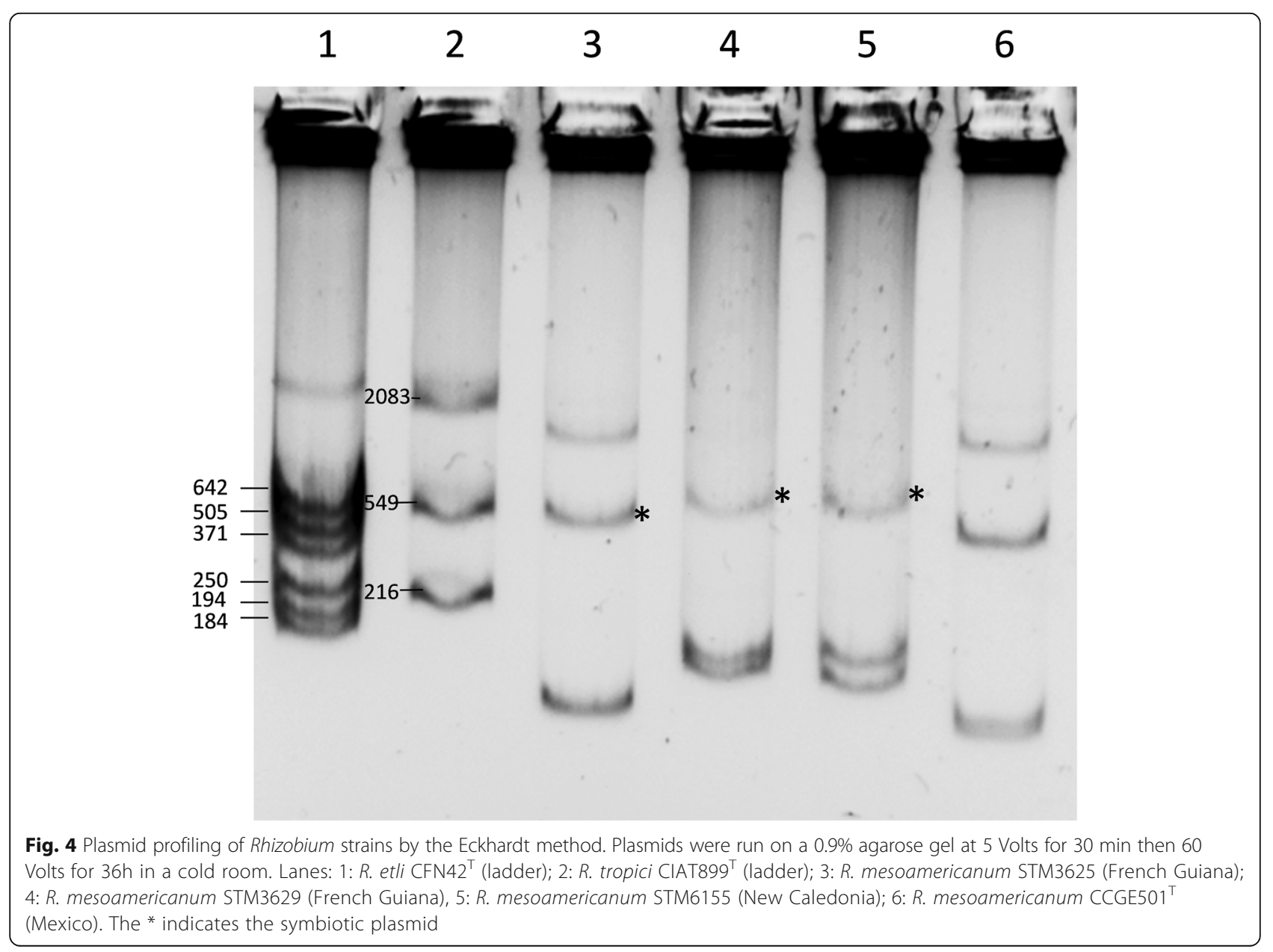


From a total of 6926 genes in the genome, 6855 were protein encoding and 71 RNA only encoding genes. The majority of genes $(76.02 \%)$ were assigned a putative function, whilst the remaining genes were annotated as hypothetical. The distribution of genes into COGs functional categories is presented in Table 4.

\section{Insights from the genome sequence}

R. mesoamericanum STM6155 shares 100 and 99\% sequence identity (over $1346 \mathrm{bp}$ ) to the $16 \mathrm{~S}$ rRNA of the fully sequenced $R$. mesoamericanum type strain CCGE501 ${ }^{\mathrm{T}}$ [45] and $R$. mesoamericanum strain STM3625 [29], respectively. Moreover the STM6155 genome shows $96.18 \%$ average nucleotide identity (ANI) (with $82 \%$ of conserved DNA), with the type strain of $R$. mesoamericanum CCGE501 ${ }^{\mathrm{T}}$ [20], fitting with the species affiliation cut-off defined by Goris et al. (2007) [46] (Table 5).

\section{Extended insights}

We produced plasmid profiles of several $R$. mesoamericanum isolates by the Eckhardt method [47] to compare their plasmid content with genomic data. As shown in Fig. 4, the STM6155 plasmid profile differs from those of STM3625 and CCGE501 ${ }^{\mathrm{T}}$. Firstly, the STM6155 and STM3629 plasmid profiles suggested the absence of a $1.5 \mathrm{Mbp}$ megaplasmid (P1) observed in CCGE501 ${ }^{\mathrm{T}}$ and STM3625. The alignment of the megaplasmid P1 sequence of STM3625 with the draft genomes of STM6155 and CCGE501 ${ }^{\mathrm{T}}$ (Fig. 5a) using progressive Mauve software [48] shows, however, the presence of P1 homologous regions in STM6155 and CCGE501 ${ }^{\mathrm{T}}$ genomes. This suggests a putative integration of megaplasmid P1 into the bacterial chromosome in STM6155. This phenomenon was already reported in cell siblings of Ensifer fredii (formerly Rhizobium sp.) NGR234 [49]. The STM6155 plasmid profile suggests thus a diversity of genome architectures at the

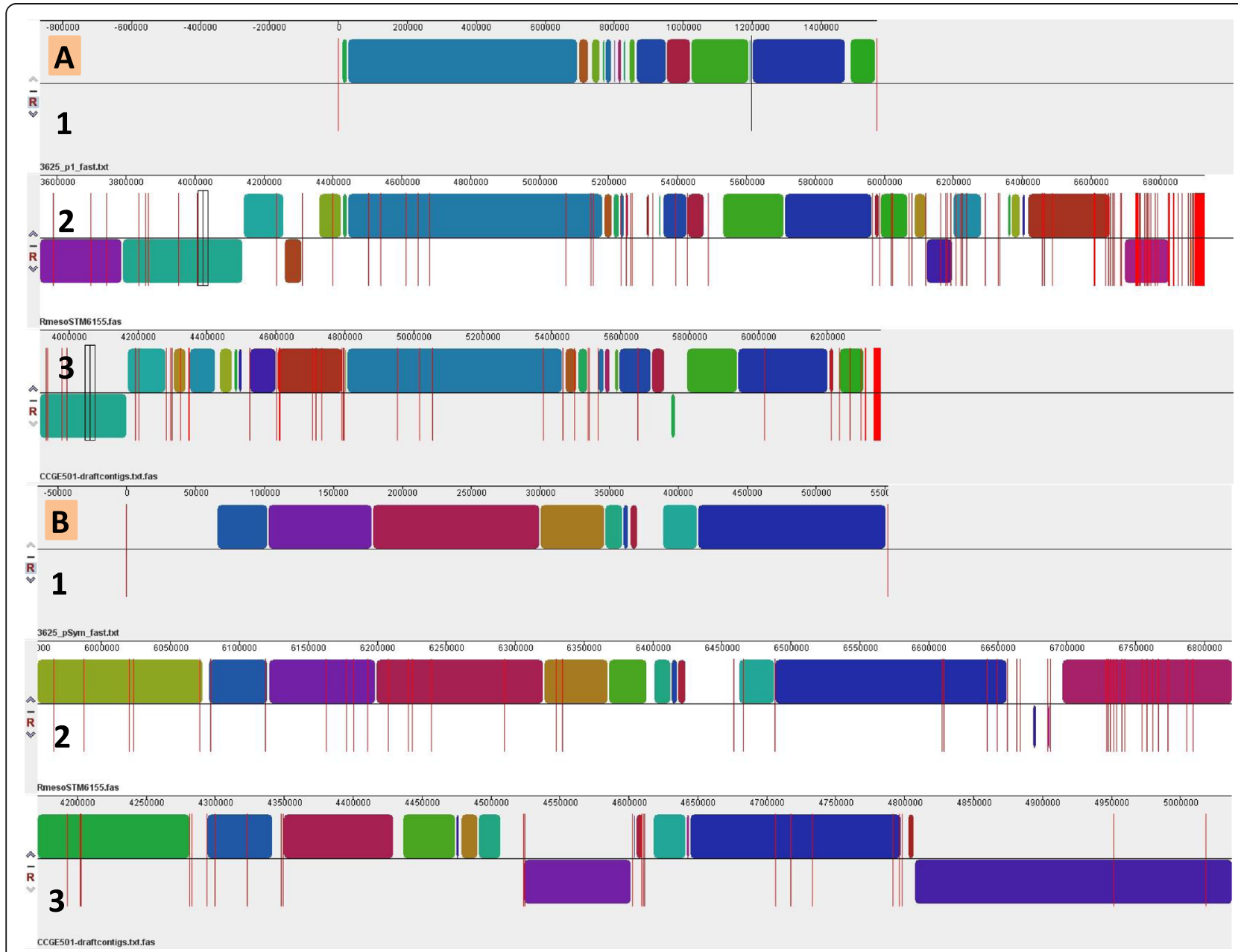

Fig. 5 Alignments (using progressive Mauve software) of STM3625 megaplasmid P1 (A1) and pSym (B1) with draft genomes of R. mesoamericanum isolates STM6155 (A2, B2) and CCGE501 ${ }^{\top}$ (A3, B3). The linked blocks in the alignment represent the common local colinear blocks (LCBs) among the compared genomes and homologous blocks among genomes are shown as identically colored regions. The red lines in A1 and B1 represent plasmid P1 boundaries (only P1 is shown), while in A2, B2, A3 and B3 they represent contigs boundaries (only homologous contigs to P1/pSym are shown) 
intra-species level in R. mesoamericanum. This diversity is observed among isolates originating from different continents like STM6155 (New Caledonia) and STM3625 (French Guiana), but also among isolates from the same country like STM3625 and STM3629 (both from French Guiana) [15, 17]. Secondly, Fig. 4 shows that STM6155 harbors a ca. $500 \mathrm{Kbp}$ symbiotic plasmid (pSym) of a slightly larger size than those of STM3625 and CCGE501 ${ }^{\mathrm{T}}$. The alignment of the STM3625 pSym with the draft genomes of STM6155 and CCGE501 ${ }^{\mathrm{T}}$ (using progressive Mauve, Fig. 5b) confirms the observed pSym size difference, with the presence of additional genomic regions in the STM3625 pSym. Althabegoiti and colleagues [45] have previously observed that there is only $61.4 \%$ of conserved DNA (with ANI of 98.07\%) between the pSyms of CCGE501 ${ }^{\mathrm{T}}$ and STM3625. Here we can extend this observation to the STM6155 pSym, which differs from both STM3625 and CCGE $501^{\mathrm{T}}$ pSyms.

Despite the sequence diversity of the pSyms within $R$. mesoamericanum isolates, the STM6155 symbiosis nodulation genes are highly conserved with those of STM3625 and CCGE501 ${ }^{\mathrm{T}}$. The STM6155 nodulation genes include nodA1BCSUIJHPQ, an additional nodA (nodA2) gene, three nodD (nodD1, 2 and 3) transcriptional regulator genes, nodM, and 2 nodO (nodO1, 2) genes. The gene order is also conserved in $R$. grahamii CCGE502 ${ }^{\mathrm{T}}$ but this strain does not contain the nodA2 allele (Fig. 6).

Strain STM6155 was isolated from a nodule of $M$. pudica growing in ultramafic soil at a $\mathrm{pH}$ near neutral (pH 6.8) that contained high concentrations of heavy metals, and the highest concentrations of bioavailable chromate among four studied sites [15]. This strain was identified as being resistant to chromate concentrations up to $0.3 \mathrm{mM}$, that is comparable with chromate tolerance of Cupriavidus metallidurans CH34 [15, 50, 51]. Chromate resistance loci (chr) have been identified in the heavy-metal-tolerant $C$. metallidurans $\mathrm{CH} 34$ and we have discovered orthologs to these genes in STM6155 (Fig. 3c), that were absent from the more chromate sensitive strain $R$. mesoamericanum STM3625. MaGe [52] analysis has revealed synteny of six of the $C$. metallidurans $\mathrm{CH} 34$ plasmid-borne chr loci in STM6155. However, in contrast to CH3, the loci in STM6155 are arranged into two putative operons, chrBAP (locus tags YY3 DRAFT_04858 - YY3DRAFT_04860) and chrCFY (locus tags YY3DRAFT_04857 - YY3DRAFT_04855) located adjacent to one another on complementary strands.

\section{Conclusions}

R. mesoamericanum STM6155 is a microsymbiont of Mimosa pudica L. and Phaseolus vulgaris L. [9], both of which have centres of origin in central/south America. The genome size of STM6155 is $6.9 \mathrm{Mbp}$ with $58.9 \%$ GC content. This strain forms a clique with the two other $R$. mesoamericanum strains STM 3625 and $\mathrm{CCGE}^{2} 1^{\mathrm{T}}$ based on average nucleotide identity comparisons (species cutoff above $95 \%$ on $>69 \%$ of conserved DNA, as defined by Goris et al. [46]. However, the genome of STM6155 has a different architecture compared with the genomes of STM3625 and CCGE501 ${ }^{\mathrm{T}}$, with STM6155 lacking a

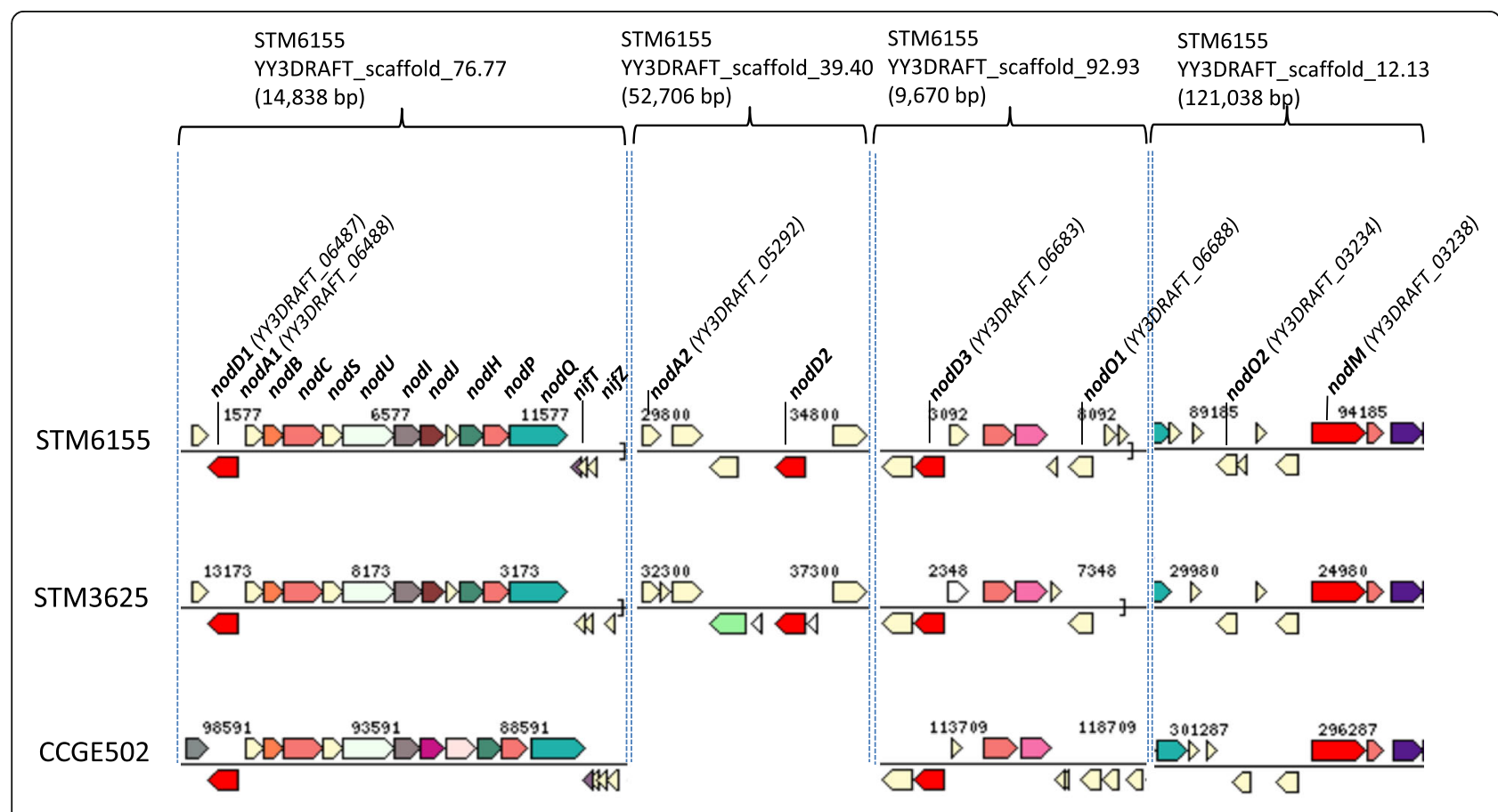

Fig. 6 Schematic organization of symbiotic genes conserved in Rhizobium mesoamericanum STM3625 and STM6155 and Rhizobium grahamii CCGE502 ${ }^{\top}$ 
megaplasmid (P1) and containing a different sized pSym and small plasmid. Although STM6155 has a larger pSym, there is a notable symbiotic nod gene conservation between the three $R$. mesoamericanum strains, which is also shared with Rhizobium grahamii CCGE502 ${ }^{\mathrm{T}}$ [20]. However, the genomes of the $R$. mesoamericanum strains contain two nodA alleles whereas $R$. grahamii CCGE502 ${ }^{\mathrm{T}}$ genome has only one. Within the STM6155 genome, we have identified a chr chromate efflux gene cluster of six genes arranged into two putative operons and we postulate that this cluster is important for the survival of STM6155 in ultramafic soils containing high concentrations of chromate. The availability of sequenced genomes of $R$. mesoamericanum should provide further insights into rhizobial biogeographic distribution and should enable free-living and symbiotic attributes to be compared with those Mimosa symbioses induced by beta-rhizobia.

\section{Additional file}

Additional file 1: Table S1. Associated MIGS record for STM6155.

Table S2. Nodulation and $\mathrm{N}_{2}$ fixation properties of Rhizobium

mesoamericanum STM6155 on selected legume hosts. (DOCX 50 kb)

\section{Abbreviations}

$1 / 2$ LA: Half strength lupin agar; ANI: Average nucleotide identity; GEBA-RNB: Genomic encyclopedia for bacteria and Archaea-root nodule bacteria; IMG: Integrated microbial genomes; TY: Tryptone-yeast extract agar

\section{Acknowledgements}

We thank Gordon Thompson (Murdoch University) for the preparation of SEM and TEM photos.

\section{Funding}

This work was performed under the auspices of the US Department of Energy's Office of Science, Biological and Environmental Research Program, and by the University of California, Lawrence Berkeley National Laboratory under contract No. DE-AC02-05CH11231. We gratefully acknowledge the funding received from the French National Agency of Research (Project BETASYM ANR-09-JCJ-0046), Curtin University Sustainability Policy Institute, and the funding received from Murdoch University Small Research Grants Scheme in 2016.

\section{Authors' contributions}

LM supplied the strain, AK and LM the background information for this project and AK, JA, LM, TR and WR drafted the manuscript. TR provided the DNA to the JGl and performed all imaging, MB and NB provided financial support and ALL, MG, DM, MH, TBKR, NV, TW, VM, NI, RS and NK were involved in sequencing the genome and/or editing the final paper. All authors read and approved the final manuscript.

\section{Competing interests}

The authors declare that they have no competing interests.

\section{Author details}

'IRD, Cirad, Univ. Montpellier, Interactions Plantes Microorganismes Environnement (IPME), 34394 Montpellier, France. ${ }^{2}$ IRD, UMR LSTM-Laboratoire des Symbioses Tropicales et Méditerranéennes, 34398 Montpellier cedex 5, France. ${ }^{3}$ School of Veterinary and Life Sciences, Murdoch University, Murdoch, WA, Australia. ${ }^{4}$ Curtin University Sustainability Policy Institute, Curtin University, Bentley, WA, Australia. ${ }^{5}$ DOE Joint Genome Institute, Walnut Creek, CA, USA. 'Biological Data Management and Technology Center, Lawrence Berkeley National Laboratory, Berkeley, CA, USA. 'Department of Biology, Faculty of Science, University of Jeddah,
Jeddah, Saudi Arabia. ${ }^{8}$ Department of Biological Sciences, Faculty of Science, King Abdulaziz University, Jeddah, Saudi Arabia.

Received: 11 June 2016 Accepted: 26 November 2016

Published online: 17 January 2017

\section{References}

1. Simon MF, Grether R, de Queiroz LP, Särkinen TE, Dutra VF, Hughes $C E$. The evolutionary history of Mimosa (Leguminosae): toward a phylogeny of the sensitive plants. Am J Bot. 2011;98:1201-21.

2. Pacific Island Ecosystems at Risk (PIER) Mimosa pudica. http://www.hear.org/ Pier/species/mimosa_pudica.htm. Accessed 21 Dec 2016.

3. Ganaie SU, Abbasi T, Abbasi SA. Green synthesis of silver nanoparticles using an otherwise worthless weed Mimosa (Mimosa pudica): Feasibility and process development toward shape/size control. Particul Sci Technol. 2015:33:638-44.

4. Ahmad H, Sehgal S, Mishra A, Gupta R. Mimosa pudica L. (Laajvanti): an overview. Pharmacogn Rev. 2012;6:115-25.

5. Joseph B, George J, Mohan J. Pharmacology and traditional uses of Mimosa pudica. Int J Pharm Sci Drug Res. 2013;5:41-4.

6. Visoottiviseth P, Francesconi K, Sridokchan W. The potential of Thai indigenous plant species for the phytoremediation of arsenic contaminated land. Environ Pollut. 2002;1 18:453-61.

7. UNDP 2015. http://www.undp.org/content/undp/en/home/sdgoverview/ post-2015-development-agenda.html. Accessed 21 Dec 2016.

8. Moulin L, Munive A, Dreyfus B, Boivin-Masson C. Nodulation of legumes by members of the beta-subclass of Proteobacteria. Nature. 2001:411:948-50.

9. Gyaneshwar P, Hirsch AM, Moulin L, Chen WM, Elliott GN, Bontemps C, Estrada-de Los Santos P, Gross E, Dos Reis FB, Sprent JI, et al. Legumenodulating betaproteobacteria: diversity, host range, and future prospects. Mol Plant Microb Interact. 2011;24:1276-88.

10. Bournaud C, de Faria SM, Dos Santos JMF, Tisseyre P, Silva M, Chaintreuil C, Gross E, James EK, Prin Y, Moulin L. Burkholderia species are the most common and preferred nodulating symbionts of the Piptadenia group (tribe Mimoseae). PLoS One. 2013;8:e63478.

11. Beukes CW, Venter SN, Law IJ, Phalane FL, Steenkamp ET. South African papilionoid legumes are nodulated by diverse Burkholderia with unique nodulation and nitrogen-fixation loci. PLoS One. 2013;8:e68406.

12. Barrett CF, Parker MA. Coexistence of Burkholderia, Cupriavidus, and Rhizobium sp. nodule bacteria on two Mimosa spp. in Costa Rica. Appl Environ Microb. 2006;72:1198-206.

13. Chen WM, Moulin L, Bontemps C, Vandamme P, Bena G, Boivin-Masson C Legume symbiotic nitrogen fixation by beta-proteobacteria is widespread in nature. J Bacteriol. 2003;185:7266-672.

14. dos Reis Jr FB, Simon MF, Gross E, Boddey RM, Elliott GN, Neto NE, de Fatima LM, de Queiroz LP, Scotti MR, Chen W-M, et al. Nodulation and nitrogen fixation by Mimosa spp. in the Cerrado and Caatinga biomes of Brazil. New Phytol. 2010;186:934-46.

15. Klonowska A, Chaintreuil C, Tisseyre P, Miché L, Melkonian R, Ducousso M, Laguerre G, Brunel B, Moulin L. Biodiversity of Mimosa pudica rhizobial symbionts (Cupriavidus taiwanensis, Rhizobium mesoamericanum) in New Caledonia and their adaptation to heavy metal-rich soils. FEMS Microbiol Ecol. 2012;81:618-35.

16. Liu X, Wei S, Wang F, James EK, Guo X, Zagar C, Xia LG, Dong X, Wang YP. Burkholderia and Cupriavidus spp. are the preferred symbionts of Mimosa spp. in southern China. FEMS Microbiol Ecol. 2012:80:417-26.

17. Mishra RP, Tisseyre P, Melkonian R, Chaintreuil C, Miche L, Klonowska A, Gonzalez S, Bena G, Laquerre G, Moulin L. Genetic diversity of Mimosa pudica rhizobial symbionts in soils of French Guiana: investigating the origin and diversity of Burkholderia phymatum and other beta-rhizobia. FEMS Microbiol Ecol. 2012;79:487-503.

18. Elliott GN, Chou J-H, Chen W-M, Bloemberg GV, Bontemps C, MartínezRomero E, Velázquez E, Young JPW, Sprent JI, James EK. Burkholderia spp. are the most competitive symbionts of Mimosa, particularly under N-limited conditions. Environ Microbiol. 2009;11:762-78.

19. Melkonian R, Moulin L, Béna G, Tisseyre P, Chaintreuil C, Heulin K, Rezkallah $\mathrm{N}$, Klonowska A, Gonzalez S, Simon M, et al. The geographical patterns of symbiont diversity in the invasive legume Mimosa pudica can be explained by the competitiveness of its symbionts and by the host genotype. Environ Microbiol. 2014;16:2099-111.

20. López-López A, Rogel-Hernández M, Barois I, Ortiz Ceballos Al, Martínez J Ormeño-Orrillo E, Martínez-Romero E. Rhizobium grahamii sp. nov. from Dalea 
leporina, Leucaena leucocephala, Clitoria ternatea nodules, and Rhizobium mesoamericanum sp. nov. from Phaseolus vulgaris, siratro, cowpea and Mimosa pudica nodules. Int J Syst Evol Microbiol. 2012;62:2264-71.

21. Bontemps C, Rogel MA, Wiechmann A, Mussabekova A, Moody S, Simon MF, Moulin L, Elliott GN, Lacercat-Didier L, Dasilva C, et al. Endemic Mimosa species from Mexico prefer alphaproteobacterial rhizobial symbionts. New Phytol. 2016;209:319-33.

22. Stopnisek N, Bodenhausen N, Frey B, Fierer N, Eberl L, Weisskopf L. Genuswide acid tolerance accounts for the biogeographical distribution of soil Burkholderia populations. Environ Microbiol. 2014;16:1503-12.

23. Reeve WG, Ardley J, Tian R, Eshragi L, Yoon JW, Ngamwisetkun P, Seshadri $R$, Ivanova NN, Kyrpides NC. A genomic encyclopedia of the root nodule bacteria: assessing genetic diversity through a systematic biogeographic survey. Stand Genom Sci. 2015;10:14.

24. Seshadri R, Reeve WG, Ardley JK, Tennessen K, Woyke T, Kyrpides NC, Ivanova NN. Discovery of novel plant interaction determinants from the genomes of 163 Root Nodule Bacteria. Sci Rep. 2015;5:16825.

25. Howieson JG, Ewing MA, D'Antuono MF. Selection for acid tolerance in Rhizobium meliloti. Plant Soil. 1988;105:179-88.

26. Beringer JE. R factor transfer in Rhizobium leguminosarum. J Gen Microbiol. 1974:84:188-98.

27. Vincent JM. A manual for the practical study of the root-nodule bacteria. International Biological Programme. Oxford: Blackwell Scientific Publications; 1970.

28. Kim O, Cho Y, Lee K, Yoon S, Kim M, Na H, Park S, Jeon Y, Lee J, Yi H, et al. Introducing EzTaxon-e: a prokaryotic 165 rRNA gene sequence database with phylotypes that represent uncultured species. Int J Syst Evol Microbiol. 2012;62:716-21

29. Moulin L, Mornico D, Melkonian R, Klonowska A. Draft genome sequence of Rhizobium mesoamericanum STM3625, a nitrogen-fixing symbiont of Mimosa pudica isolated in French Guiana (South America). Genome Announc. 2013;1:e00066-00012.

30. Reddy TBK, Thomas AD, Stamatis D, Bertsch J, Isbandi M, Jansson J, Mallajosyula J, Pagani I, Lobos EA, Kyrpides NC. The Genomes OnLine Database (GOLD) v.5: a metadata management system based on a four level (meta)genome project classification. Nucleic Acids Res. 2015;43:D1099-106.

31. Markowitz VM, Chen IA, Palaniappan K, Chu K, Szeto E, Pillay M, Ratner A, Huang J, Woyke T, Huntemann M, et al. IMG 4 version of the integrated microbial genomes comparative analysis system. Nucleic Acids Res. 2014;42:D560-67

32. Joint Genome Institute Protocols. http://jgi.doe.gov/user-program-info/pmooverview/protocols-sample-preparation-information/. Accessed 21 Dec 2016.

33. Bennett S. Solexa Ltd. Pharmacogenomics. 2004;5:433-38.

34. Joint Genome Institute. http://jgi.doe.gov/. Accessed 21 Dec 2016

35. Zerbino DR. Using the velvet de novo assembler for short-read sequencing technologies. Curr Protoc Bioinformatics. 2010;11(11):15.

36. GitHub - Ih3/wgsim: Reads simulator. https://github.com/lh3/wgsim Accessed 21 Dec 2016

37. Gnerre S, MacCallum I, Przybylski D, Ribeiro FJ, Burton JN, Walker BJ, Sharpe T, Hall G, Shea TP, Sykes S, et al. High-quality draft assemblies of mammalian genomes from massively parallel sequence data. Proc Natl Acad Sci U S A. 2011;108:1513-518.

38. Hyatt $\mathrm{D}, \mathrm{Chen} \mathrm{GL}$, Locascio PF, Land ML, Larimer FW, Hauser L. Prodigal: prokaryotic gene recognition and translation initiation site identification. BMC Bioinform. 2010;11:119.

39. Chen IMA, Markowitz VM, Chu K, Anderson I, Mavromatis K, Kyrpides NC, Ivanova NN. Improving microbial genome annotations in an integrated database context. PLoS One. 2013;8:e54859.

40. Huntemann M, Ivanova NN, Mavromatis K, Tripp HJ, Paez-Espino D, Palaniappan K, Szeto E, Pillay M, Chen IM-A, Pati A, et al. The standard operating procedure of the DOE-JGI microbial genome annotation pipeline (MGAP v.4). Stand Genom Sci. 2015;10:86

41. Lowe TM, Eddy SR. tRNAscan-SE: a program for improved detection of transfer RNA genes in genomic sequence. Nucleic Acids Res. 1997;25:955-64.

42. Pruesse E, Quast C, Knittel K, Fuchs BM, Ludwig W, Peplies J, Glöckner FO. SILVA: a comprehensive online resource for quality checked and aligned ribosomal RNA sequence data compatible with ARB. Nucleic Acids Res. 2007;35:7188-196.

43. Nawrocki EP, Eddy SR. Infernal 1.1: 100-fold faster RNA homology searches. Bioinformatics. 2013;29:2933-935.
44. Markowitz VM, Mavromatis K, Ivanova NN, Chen IM, Chu K, Kyrpides NC. IMG ER: a system for microbial genome annotation expert review and curation. Bioinformatics. 2009;25:2271-78.

45. Althabegoiti MJ, Ormeño-Orrillo E, Lozano L, Torres Tejerizo G, Rogel MA, Mora J, Martínez-Romero E. Characterization of Rhizobium grahamii extrachromosomal replicons and their transfer among rhizobia. BMC Microbiol. 2014;14:6.

46. Goris J, Konstantinidis KT, Klappenbach J, Coenye T, Vandamme P, Tiedje JM. DNA-DNA hybridization values and their relationship to whole-genome sequence similarities. Int J Syst Evol Microbiol. 2007;57:81-91.

47. Eckhardt T. A rapid method for the identification of plasmid deoxyribonucleic acid in bacteria. Plasmid. 1978;1:584-88.

48. Darling AE, Mau B, Perna NT. progressiveMauve: multiple genome alignment with gene gain, loss and rearrangement. PLoS One. 2010;5:e11147.

49. Mavingui P, Flores M, Guo X, Dávila G, Perret X, Broughton WJ, Palacios R. Dynamics of genome architecture in Rhizobium sp. strain NGR234. J Bacteriol. 2002;184:171-76.

50. Janssen PJ, Van Houdt R, Moors H, Monsieurs P, Morin N, Michaux A, Benotmane MA, Leys N, Vallaeys T, Lapidus A, et al. The complete genome sequence of Cupriavidus metallidurans strain $\mathrm{CH} 34$, a master survivalist in harsh and anthropogenic environments. PLoS One. 2010;5:e10433.

51. Juhnke S, Peitzsch N, Hübener N, Große C, Nies DH. New genes involved in chromate resistance in Ralstonia metallidurans strain CH34. Arch Microbiol. 2002;179:15-25.

52. Vallenet D, Labarre L, Rouy Z, Barbe V, Bocs S, Cruveiller S, Lajus A, Pascal G, Scarpelli C, Medique C. MaGe: a microbial genome annotation system supported by synteny results. Nucleic Acids Res. 2006;34:53-65.

53. Tamura K, Peterson D, Peterson N, Stecher G, Nei M, Kumar S. MEGA5: molecular evolutionary genetics analysis using maximum likelihood, evolutionary distance, and maximum parsimony methods. Mol Biol Evol. 2011;28:2731-739.

54. Nei M, Kumar S. Molecular evolution and phylogenetics. New York: Oxford University Press; 2000

55. Felsenstein J. Confidence limits on phylogenies: an approach using the bootstrap. Evolution. 1985:39:783-91.

56. Field D, Garrity G, Gray T, Morrison N, Selengut J, Sterk P, Tatusova T, Thomson N, Allen M, Angiuoli SV, et al. Towards a richer description of our complete collection of genomes and metagenomes "minimum information about a genome sequence" (MIGS) specification. Nat Biotechnol. 2008;26:541-7.

57. Field D, Amaral-Zettler L, Cochrane G, Cole JR, Dawyndt P, Garrity GM, Gilbert J, Glöckner FO, Hirschman L, Karsch-Mizrachi I, et al. The genomic standards consortium. PLoS Biol. 2011;9:e1001088.

58. Woese CR, Kandler O, Wheelis ML. Towards a natural system of organisms: proposal for the domains archaea, bacteria, and eucarya. Proc Natl Acad Sci U S A. 1990;87:4576-579

59. Editor L. Validation of publication of new names and new combinations previously effectively published outside the IJSEM. Int Syst Evol Micr. 2005:55:2235-238

60. Chen WX, Wang ET, Kuykendall LD. The Proteobacteria. New York: Springer Verlag; 2005.

61. Garrity GM, Bell JA, Lilburn T: Class I. Alphaproteobacteria class. In: Garrity GM, Brenner DJ, Kreig NR, Staley JT, editors. Bergey's manual of systematic bacteriology. 2nd ed. New York: Springer - Verlag; 2005.

62. Kuykendall LD. Order VI. Rhizobiales ord. nov. In: Garrity GM, Brenner DJ, Kreig NR, Staley JT, editors. Bergey's manual of systematic bacteriology. 2nd ed. New York: Springer - Verlag; 2005. p. 324.

63. Kuykendall LD. Family I. Rhizobiaceae. In: Garrity GM, Brenner DJ, Krieg NR, Staley JT, editors. Bergey's manual of systematic bacteriology. New York: Springer - Verlag; 2005.

64. Biological Agents: Technical rules for biological agents. http://www.baua.de/en/ Topics-from-A-to-Z/Biological-Agents/TRBA/TRBA.html. Accessed 21 Dec 2016.

65. Ashburner M, Ball CA, Blake JA, Botstein D, Butler H, Cherry JM, Davis AP, Dolinski K, Dwight SS, Eppig JT, et al. Gene ontology: tool for the unification of biology. The gene ontology consortium. Nat Genet. 2000;25:25-9.

66. Guide to GO Evidence Codes. http://geneontology.org/page/guide-goevidence-codes. Accessed 21 Dec 2016.

67. Rhizobium mesoamericanum STM6155 Genome sequencing and assembly. http://www.ncbi.nlm.nih.gov/bioproject/?term=YY3. Accessed 21 Dec 2016.

68. Richter M, Rosselló-Móra R. Shifting the genomic gold standard for the prokaryotic species definition. Proc Natl Acad Sci U S A. 2009:106:19126-131. 